\title{
ANIMASI E-LEARNING PEMBELAJARAN MATEMATIKA DAN FISIKA BAGI SISWA SEKOLAH MENENGAH PERTAMA KELAS 1
}

\author{
Nurcahyani Dewi Retnowati ${ }^{1}$, Mahmuda Ghazni Rahmawan ${ }^{2}$ \\ Prodi Teknik Informatika \\ Sekolah Tinggi Teknologi Adisutjipto \\ J1. Janti Blok R, Lanud Adisutjipto, Yogyakarta \\ ${ }^{1}$ ndewiret@gmail.com
}

\begin{abstract}
Learning through the use of animation E-Learning can be a learning tool to teach using electronic applications, media, Internet, Intranet or other computer network media. In addition to computers and Internet networks, which play a role in e-learning is the brainware that is creating content (text, images, video, animation) and user/users of e-learning (teachers and students). It should be noted in making animated e-learning is the content that should be included in accordance with the curriculum that is used by the school to be used for teaching and learning in schools. Making animated blueprint of learning by using characters then do modeling and animation. The subjects used in this study animation is Mathematics and Physics. Software used in the manufacture of learning applications that 3ds Max 2010, Adobe Premiere Pro CC, Adobe After Effects. The analysis tested the effectiveness of learning communication using questionnaire and calculation using a Likert scale that shows the percentage of $69.83 \%$, the analysis proves that by using an animated e-learning teaching and learning activities in the classroom more effectively.
\end{abstract}

Keywords: Internet, Learning, Lesson

\begin{abstract}
Abstrak
Pembelajaran melalui penggunaan animasi E-Learning dapat menjadi suatu sarana belajar mengajar dengan menggunakan aplikasi elektronik, media Internet, Intranet atau media jaringan komputer lain. Selain komputer dan jaringan internet, yang berperan dalam e-learning adalah brainware yaitu yang membuat konten (tulisan, gambar, video, animasi) dan pemakai/pengguna $e$ learning (guru dan siswa/i). Perlu diperhatikan dalam membuat animasi e-learning adalah isi konten yang dimasukkan harus sesuai dengan kurikulum yang yang digunakan oleh sekolah agar bisa dipakai untuk proses belajar dan mengajar di sekolah. Pembuatan animasi pembelajaran dengan menggunakan blueprint karakter kemudian dilakukan pemodelan dan animasi. Mata pelajaran yang digunakan dalam animasi pembelajaran ini adalah Matematika dan Fisika. Software yang digunakan dalam pembuatan aplikasi pembelajaran yaitu $3 d s$ Max 2010, Adobe Premiere Pro CC, Adobe After Effect. Analisis pengujian keefektifan komunikasi pembelajaran menggunakan kuisioner dan perhitungannya menggunakan skala Likert yang menunjukan persentase sebesar $69,83 \%$, hasil analisis tersebut membuktikan bahwa dengan menggunakan animasi e-learning kegiatan belajar mengajar di kelas menjadi lebih efektif.
\end{abstract}

Kata kunci: Internet, Belajar mengajar, Pelajaran 


\section{Pendahuluan}

Animasi dapat juga diartikan sebagai menggerakan suatu gambar atau obyek yang diam. Animasi merupakan gambar bergerak yang disusun dari satu atau sekumpulan objek yang disusun secara teratur mengikuti alur pergerakan yang telah ditentukan pada setiap pertambahan waktu yang terjadi. Obyek tersebut dapat berupa gambar makhluk hidup, benda mati, ataupun tulisan. Obyek tersebut ditampilkan secara berurutan sehingga menghasilkan suatu ilusi gerakan yang disebut dengan motion.

E-learning merupakan singkatan dari Electronic Learning, merupakan cara baru dalam proses belajar mengajar yang menggunakan media elektronik khususnya internet sebagai sistem pembelajarannya. E-learning adalah suatu sistem atau konsep pendidikan yang memanfaatkan teknologi informasi dalam proses belajar mengajar. Pembelajaran yang disusun dengan tujuan menggunakan sistem elektronik atau komputer sehingga mampu mendukung proses pembelajaran.

Proses belajar mengajar di sekolah dinilai sangat membuat bosan untuk beberapa anak, terutama untuk sekolah yang telah menerapkan sistem full day school. Dampak dari bosan adalah menjadi kurang tertariknya siswa/i untuk mengikuti proses belajar mengajar.

Untuk mengatasi kendala tersebut, maka perlu dibuat sebuah desain pembelajaran yang dapat menghilangkan rasa bosan, dan membuat siswa/i tetap fokus dalam belajar. Animasi $E-$ Learning ini diharapkan menjadi salah satu solusi media pembelajaran yang menarik untuk siswa/i, khususnya siswa/i kelas 1 SMP dan sekaligus menjadikan komunikasi saat kegiatan belajar mengajar menjadi lebih efektif.

\section{Metode}

Metode yang digunakan dalam pembuatan animasi pembelajaran yaitu dengan metode pengumpulan data, metode analisis data yang dimulai dari perancangan yang terdiri dari penentuan spesifikasi hardware dan software yang digunakan, pembuatan flowchart atau alur kerja, pembuatan karakter dan pembuatan animasi baik itu animasi 2D maupun 3D, serta juga digunakan metode analisis data pengujian.

\subsection{Metode Pengumpulan Data}

Metode pengumpulan data yang dilakukan adalah dengan mencari data materi pelajaran Matematika dan Fisika yang sesuai dengan kurikulum yang diterapkan di sekolah, dalam hal ini adalah Sekolah Menengah Pertama kelas 1, selain itu juga mencari referensi tentang pembuatan alur kerja dan pembuatan animasi 2D dan 3D.

\subsection{Metode Analisis Data}

Metode analisis data dimulai dari perancangan penentuan spesifikasi hardware dan software yang digunakan dalam pembuatan animasi pembelajaran, pembuatan flowchart atau alur kerja menggunakan Visio, pembuatan karakter dengan pemodelan, pembuatan animasi 2D dan 3D dengan menggunakan 3ds Max 2010, Adobe Premiere Pro CC, Adobe After Effect, serta pengujian aplikasi dengan menggunakan kuisioner disertai perhitungan dengan menggunakan skala Likert. 


\section{Hasil dan Pembahasan}

\subsection{Spesifikasi Hardware dan Software}

Dalam pembuatan animasi pembelajaran diperlukan adanya perangkat keras (hardware) dan perangkat lunak (software).

Perangkat keras yang digunakan dalam perancangan dan pembuatan animasi ini adalah sebagai berikut: Processor AMD Phenom ${ }^{\mathrm{TM}}$ X4 955 BE @3.40GHz (4CPUs), 3.4GHz, RAM 4.00GB, Harddisk $1500 \mathrm{~GB}, B D-R O M$ dan DVD-RW, VGAAMD Radeon HD667OC, Headphone built in mic.

Perangkat lunak yang digunakan dalam pembuatan animasi ini adalah: Windows 7 Ultimate, 3ds Max 2010, Adobe Premiere Pro CC, Adobe After Effect.

\subsection{Pemodelan}

Dalam animasi 3D, khusus untuk modeling karakter dibuat dalam satuan vertex, kemudian ditempel atau dibalut dengan texture sehingga pengguna dapat melihat dengan jelas modeling karakter terbuat dari bahan apa, misal texture kulit, wajah, kain, bulu, rambut, manik-manik, dan sebagainya. Agar modeling ini dapat bergerak, kita harus memberikan rigging, sehingga modeling tersebut bisa bergerak seperti layaknya manusia. Agar terlihat lebih ekspresif pada bagian wajah, kita membuat facial expression dan lip sync.

Background dalam 3D dapat dibuat dengan me-modeling bangunan, hutan, gunung, dan lainnya. Sebagai langkah terakhir agar hasil animasinya lebih sempurna ditambahkan effect gambar lainnya seperti debu, angin, hujan, petir, air, banjir, dan lain-lain.

Blueprint merupakan sebuah rancangan yang dirumuskan dengan tujuan untuk memberikan arahan untuk merancang dan membuat sebuah animasi, karena itu dibutuhkan blueprint untuk membuat model agar sesuai dengan desain yang sudah dirancang di atas kertas. Blueprint hanya digunakan untuk pemodelan alien, contoh blueprint seperti pada gambar 1.

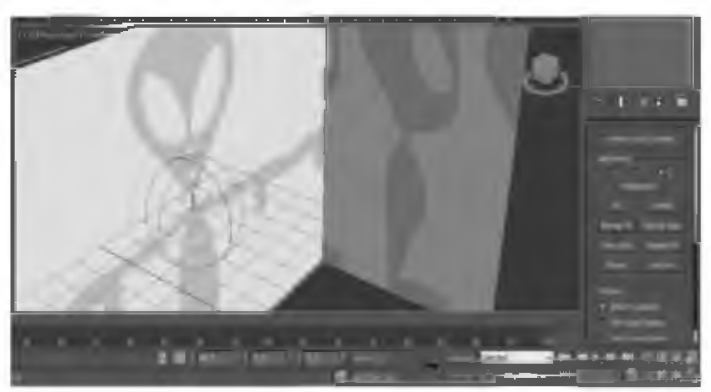

Gambar 1. Contoh Blueprint

3D modeling (pemodelan) adalah proses mengembangkan matematika representasi dari setiap tiga-dimensi benda (baik benda mati atau hidup) melalui perangkat lunak khusus.

Hal ini dapat ditampilkan sebagai gambar dua dimensi (2D) melalui proses yang disebut $3 \mathrm{D}$ rendering atau digunakan dalam komputer simulasi fenomena fisik. Contoh 3D Modeling bisa dilihat seperti pada gambar 2 . 
Nurcahyani Dewi Retnowati, Mahmuda Ghazni Rahmawan

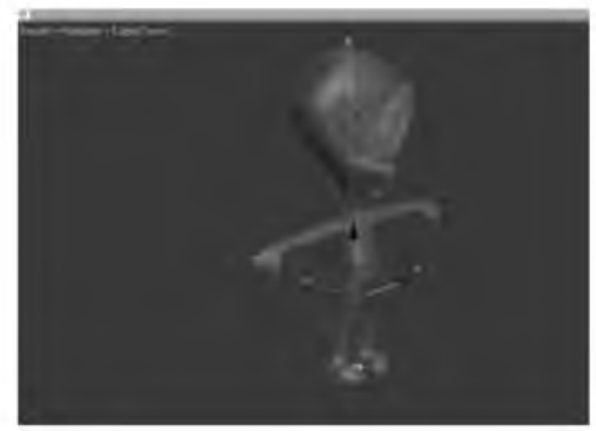

Gambar 2. Contoh 3D modeling

Animating adalah suatu proses di mana para animator menggerakkan suatu objek $3 \mathrm{~d} /$ karakter $3 \mathrm{~d}$ secara digital sesuai dengan yang diharapkan, proses ini dilakukan setelah melakukan proses rigging ataupun skinning. Contoh animating dapat dilihat pada gambar 3.

Skinning adalah mengelompokkan beberapa vertex menjadi beberapa group. Contoh skinning dapat dilihat pada gambar 4 .

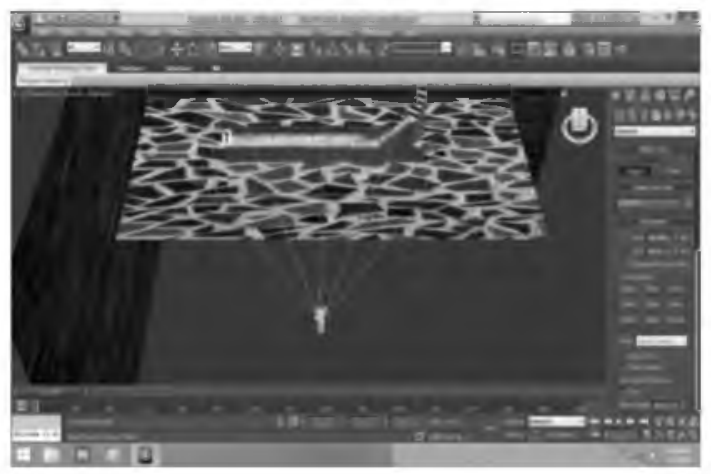

Gambar 3. Contoh Animating

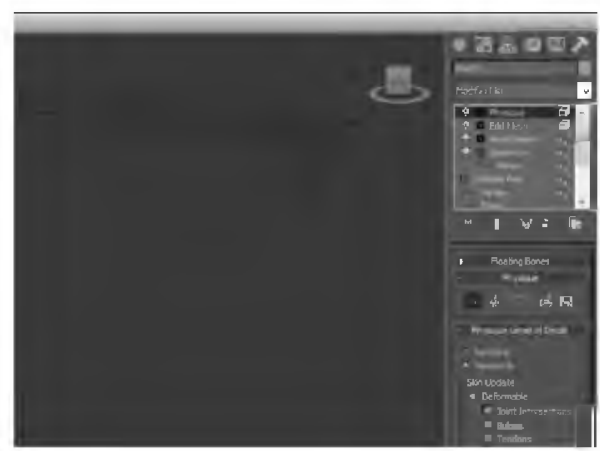

Gambar 4. Contoh Skinning

Rigging adalah proses pembuatan pertulangan (Armature) yang tersusun dari beberapa tulang (Bone) yang saling berhubungan. Rigging seperti pada gambar 5 digunakan agar animasi bisa bergerak layaknya manusia. 


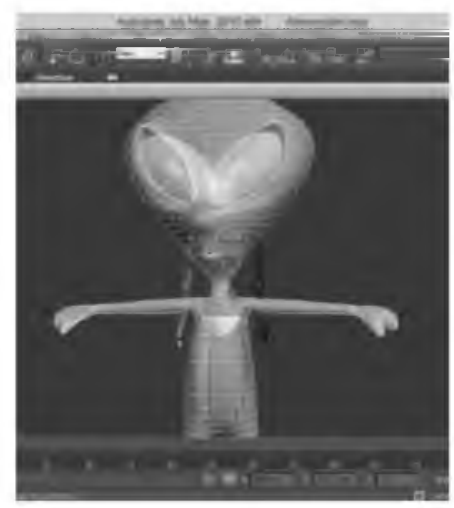

Gambar 5. Contoh Rigging

Texturing seperti pada gambar 6 adalah proses pemberian karakteristik permukaan termasuk warna, highlight, kilauan, sebaran cahaya (difusi) dan lainnya pada obyek. Karakteristik seperti bump juga diperhatikan saat proses texturing. Pada umumnya proses texturing adalah semacam pengecatan atau pemberian warna pada permukaan obyek, walaupun ada juga proses texturing seperti displacement yang mengubah geometri obyek.

Rendering merupakan proses akhir dari keseluruhan proses pemodelan ataupun animasi komputer. Dalam rendering, semua data yang sudah dimasukkan dalam proses modeling, animasi, texturing, pencahayaan dengan parameter tertentu akan diterjemahkan dalam sebuah bentuk output (tampilan akhir pada model dan animasi). Contoh proses rendering dapat dilihat pada gambar 7 .

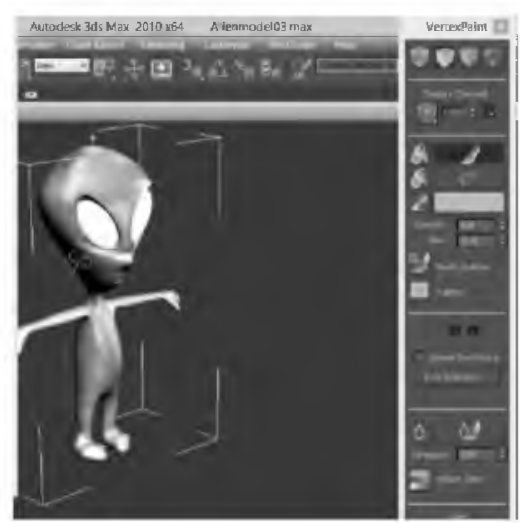

Gambar 6. Texturing

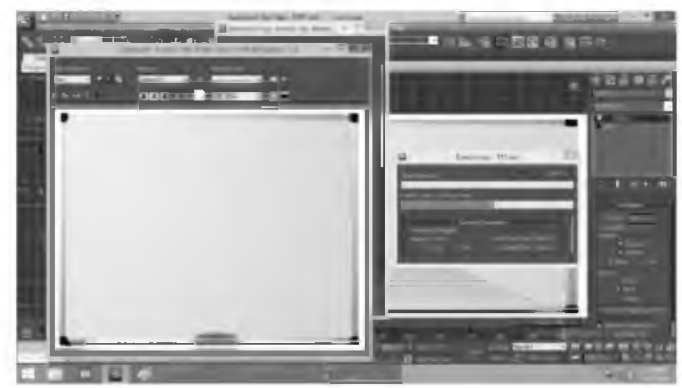

Gambar 7. Contoh Proses Rendering 


\subsection{Flowchart}

Pada perancangan flowchart pemodelan Animasi E-Learning dibawah terdapat beberapa proses penting pada pembuatannya, yaitu proses input blueprint, proses modeling dan penggabungan beberapa gambar materi yang di-input di dalam Animasi E-Learning. Penjelasan alur pemodelan Animasi E-Learning dapat dilihat pada gambar 8 .

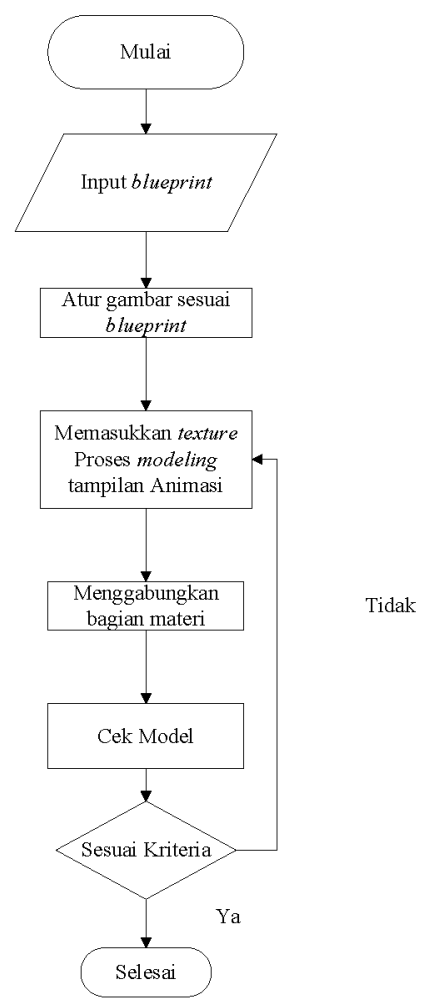

Gambar 8. Flowchart Pemodelan Tampilan Animasi E-Learning

Pada flowchart proses editing video (Gambar 9) terdapat beberapa langkah pada proses pembuatannya. Perlu dipahami adalah hasil editing akan ditentukan oleh kreativitas brainware-nya (pembuat animasi pembelajaran).

\subsection{Tampilan Animasi 2D dan 3D}

Setelah dilakukan pemodelan karakter dan pembuatan flowchart alur kerja, baik flowchart pemodelan tampilan animasi pembelajaran maupun flowchart proses editing, maka selanjutnya dibuat animasi matematika maupun animasi fisika.

Animasi Matematika yang dibuat meliputi animasi bangun datar dan bangun ruang. Animasi bangun datar hanya sebatas animasi 2D dikarenakan bangun datar adalah bangun yang tidak memiliki ruang atau volume.

Animasi Matematika Bangun Datar berupa animasi 3D dikarenakan bangun ruang memiliki ruang atau volume.

Tampilan animasi bangun datar dapat dilihat pada gambar 10 dan animasi bangun ruang dapat dilihat pada gambar 11 . 


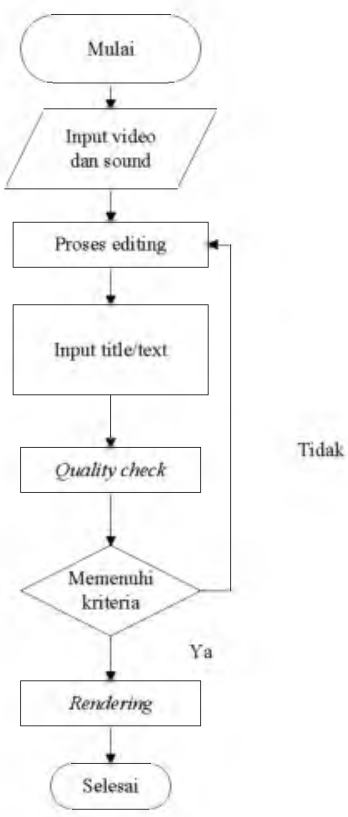

Gambar 9. Flowchart Proses Editing

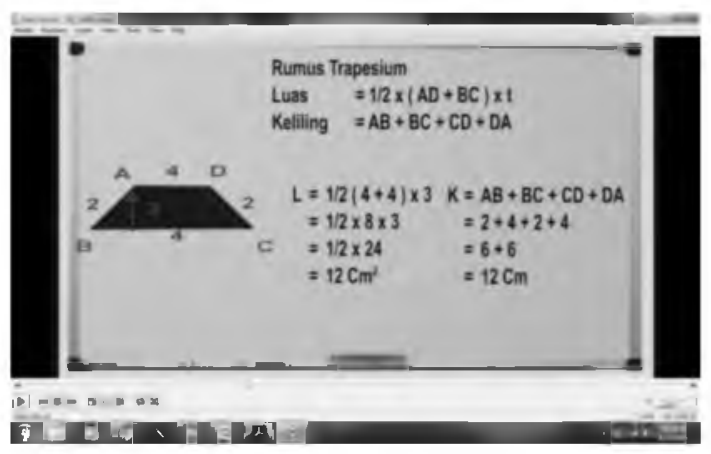

Gambar 10. Animasi Bangun Datar

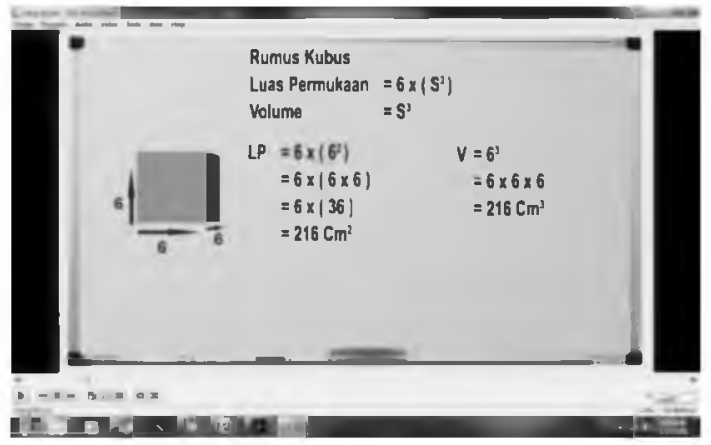

Gambar 11. Animasi Bangun Ruang

Animasi Fisika terdiri atas materi Gerak Lurus berupa animasi 3D yang bergerak sesuai dengan materi yang diberikan, yaitu gerak lurus beraturan, gerak lurus berubah beraturan, dan gerak lurus berubah beraturan dipercepat. Tampilan animasi Fisika dapat dilihat pada gambar 12. 


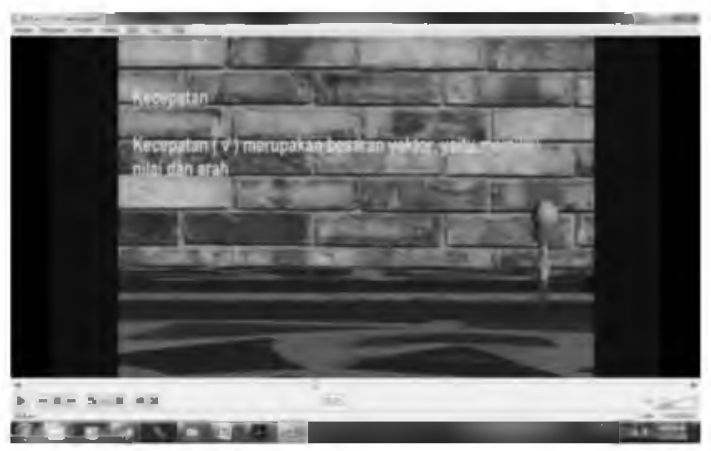

Gambar 12. Animasi Gerak Lurus

\subsection{Pengujian}

Animasi E-Learning ini dibuat untuk memudahkan guru dalam proses belajar mengajar. Guru mempersilahkan siswa/i untuk menyaksikan video animasi ini dan menambah sedikit materi penjelasan yang tidak ada dalam animasi ini.

Uji coba dan uji pengguna dilakukan untuk mengetahui keefektifan dan kelayakan animasi ini di dalam proses belajar mengajar. Uji coba dilakukan dengan cara menyebar kuisioner kepada guru-guru SMP yang ada di kota Yogyakarta untuk dinilai, dengan jumlah total kuisioner 36 responden yaitu 36 guru SMP dan dengan jumlah pertanyaan 10.

Perhitungan penilaian kuosioner menggunakan skala Likert. Skala Likert digunakan untuk mengukur sikap, pendapat dan persepsi seseorang atau sekelompok orang mengenai fenomena sosial. Kelebihan pengukuran dengan menggunakan skala Likert: skor yang tinggi menunjukkan sikap yang lebih tinggi dibandingkan dengan skor yang rendah, mempunyai reliabilitas tinggi dalam mengurutkan manusia berdasarkan intensitas sikap tertentu. Skor untuk tiap pernyataan juga mengukur intensitas sikap responden terhadap pernyataan tersebut.

Berdasarkan perhitungan -perhitungan pada kuisioner yang telah ditujukan pada guru, dengan menggunakan skala Likert maka didapatkan hasil sebesar 69, 83\%. Hal tersebut menunjukkan bahwa dengan adanya animasi pembelajaran akan dapat meningkatkan keefektifan komunikasi dalam kegiatan belajar mengajar di kelas.

Tabel 1. Hasil Perhitungan Kuisioner

\begin{tabular}{lcc}
\hline Pertanyaan & Total Skor & \% Skor \\
\hline Tampilan & 119 & 66,11 \\
Informasi & 123 & 68,33 \\
Kemudahan & 130 & 72,22 \\
Manfaat & 145 & 80,55 \\
Efektif & 129 & 71,67 \\
Kelayakan & 121 & 67,22 \\
Komunikasi & 126 & 70 \\
Kejelasan & 118 & 65,55 \\
Kesesuaian & 124 & 68,88 \\
Efisien & 122 & 67,77 \\
& & \\
\hline
\end{tabular}

Jumlah \% Skor adalah $698,33 \%$ 
Tabel 2. Persentase Nilai

\begin{tabular}{|l|l|}
\hline Keterangan & Jawaban \\
\hline Sangat Kurang & $0 \%-19.99 \%$ \\
\hline Kurang & $20 \%-39.99 \%$ \\
\hline Cukup & $40 \%-59.99 \%$ \\
\hline Baik & $60 \%-79.99 \%$ \\
\hline
\end{tabular}
berikut:

Pengujian Rata-rata pada Hasil Penilaian Guru berdasarkan data di atas adalah sebagai

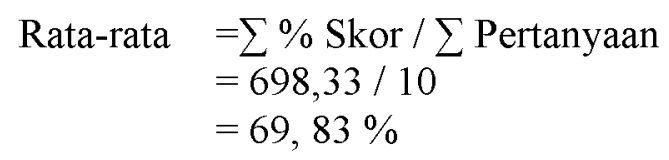

Dengan perolehan persentase $69.83 \%$ dan mengacu pada Tabel 2 maka dapat disimpulkan bahwa animasi ini tergolong baik dan dapat mendukung keefektifan komunikasi dalam pembelajaran.

\section{Kesimpulan Dan Saran}

\subsection{Kesimpulan}

Dari hasil pengujian dan analisis yang telah dibahas sebelumnya maka dapat disimpulkan beberapa hal yaitu:

1. Animasi mata pelajaran Matematika dan Fisika dapat dijalankan dengan baik.

2. Hasil pengujian dengan menggunakan kuisioner sebanyak 36 responden dan 10 pertanyaan mendapat nilai persentase sebesar $69.83 \%$ menunjukkan bahwa komunikasi pembelajaran dengan menggunakan animasi menjadi lebih efektif.

\subsection{Saran}

Fitur-fitur yang bisa ditambahkan pada animasi ini adalah sebagai berikut :

1. Menambahkan beberapa materi yang belum diaplikasikan di video ini.

2. Menambahkan latihan soal untuk dikerjakan siswa

3. Dapat ditambahkan materi pelajaran lain sehingga pembelajaran menggunakan animasi menjadi lebih bervariasi

\section{Daftar Pustaka}

Andi. 2008. Editing Video Dengan Adobe Premier Pro. Andi Offset: Yogyakarta.

Hamzah, A. 2007. 7 Objek Realistik 3ds Max. Maxikom, Palembang.

Hendratman, H. 2008. The Magic of 3D Studio Max, Informatika Bandung, Bandung.

Hendri, Hendramat. 2009. The Magic of Adobe After Effects. Penerbit Informatika: Bandung. 
Nurcahyani Dewi Retnowati, Mahmuda Ghazni Rahmawan

Masnur Muslich. 2007. KTSP Pembelajaran Berbasis Kompetensi Dan Kontekstual Panduan Bagi Guru, Kepala Sekolah, Dan Pengawas Sekolah. Bumi Aksara: Jakarta.

Zaharuddin G. Djalle. 2006. The Making of 3D Animation Movie using 3DStudio Max. Informatika: Bandung.

Saiffuddin, Juhri, The Using Of Comic For Social Studies Learning At Secondary School, [Online], Diakses di:

http:/www.academia.edu/4063794/the_using_of_comic_for_social_studies_learning_at secondary_school [10 Juli 2016] 